\title{
FORMAÇÃO DE PROFESSORES PARA A EDUCAÇÃO INFANTIL: CAMINHOS TRILHADOS $^{1}$
}

\author{
Maria de Fátima Avelino da Silva, Universidade Federal de Campina Grande/UFCG, \\ mafasilva.sjp@gmail.com
}

Maria Gracielle Vieira Pedroza, Universidade Federal de Campina Grande/UFCG, gracielle.1997@hotmail.com

\author{
Zildene Francisca Pereira, Universidade Federal de Campina Grande/UFCG, \\ denafran@yahoo.com.br
}

\begin{abstract}
RESUMO
Apresentaremos, neste artigo, uma breve reflexão acerca de aspectos históricos que permeiam a formação de professores para a Educação Infantil, a partir dos avanços e entraves nas políticas públicas voltadas para essa etapa da educação básica. Para tanto temos como objetivo: discutir as principais influências para a escolha da profissão docente, levando em consideração a contribuição das experiências vividas e as limitações no que diz respeito às oportunidades de emprego/trabalho na cidade onde residimos, bem como reconhecer a importância dos vínculos estabelecidos entre professores e alunos para o processo de ensino-aprendizagem e identificar os principais aspectos vividos nas experiências escolares que contribuíram de forma agradável e/ou desagradável refletidas na prática docente. Realizamos uma entrevista semiestruturada contendo cinco questões acerca da escolha da profissão docente, com uma professora que trabalha na Educação Infantil na cidade de Carrapateira/PB. Vimos a partir da narrativa da professora que a escolha da docência está ligada as próprias condições sociais e econômicas da cidade onde reside, a influência do modelo de professora que teve quando criança e a relevância de trabalhar na Educação Infantil considerando as diferentes aprendizagens dos alunos em seu contexto específico. Por fim, Essa atividade nos possibilitou pensar a escolha da docência a partir de um olhar mais cuidadoso acerca da formação e dos principais aspectos que a influenciam.
\end{abstract}

PALAVRAS-CHAVE: Formação Docente; Educação Infantil; Escolha da profissão.

\begin{abstract}
We present in this article a brief reflection on the historical aspects that permeate the formation of teachers for Early Childhood Education, starting from the advances and obstacles in the public policies directed to this stage of basic education. To that end, we aim to: discuss the main influences on the choice of the teaching profession, taking into account the contribution of the lived experiences and the limitations with regard to employment / work opportunities in the city where we live, as well as to recognize the importance of the links Established between teachers and students for the teachinglearning process and identify the main aspects of the school experiences that contributed in a pleasant

\footnotetext{
${ }^{1} \mathrm{O}$ presente trabalho (não) contou com apoio financeiro de nenhuma natureza para sua realização.
} 
and / or unpleasant way reflected in the teaching practice. We conducted a semistructured interview containing five questions about the choice of the teaching profession, with a teacher who works in Early Childhood Education in the city of Carrapateira / PB. We saw from the narrative of the teacher that the choice of teaching is linked to the social and economic conditions of the city where she resides, the influence of the teacher model she had as a child and the relevance of working in Early Childhood Education considering the different learnings of the students in Context. Finally, this activity enabled us to think about the choice of teaching from a more careful look at the formation and the main aspects that influence it.

KEYWORDS: Teacher Training; Child education; Choice of profession.

\section{RESUMEN}

En este artículo presentaremos brevemente una breve reflexión acerca de aspectos históricos que permean la formación de profesores para la Educación Infantil, a partir de los avances y obstáculos en las políticas públicas orientadas hacia esa etapa de la educación básica. Para ello tenemos como objetivo: discutir las principales influencias para la elección de la profesión docente, teniendo en cuenta la contribución de las experiencias vividas y las limitaciones en lo que se refiere a las oportunidades de empleo / trabajo en la ciudad donde residimos, así como reconocer la importancia de los vínculos Establecidos entre profesores y alumnos para el proceso de enseñanza-aprendizaje e identificar los principales aspectos vividos en las experiencias escolares que contribuyeron de forma agradable y / o desagradable reflejadas en la práctica docente. Realizamos una entrevista semiestructurada conteniendo cinco cuestiones acerca de la elección de la profesión docente, con una profesora que trabaja en la Educación Infantil en la ciudad de Carrapateira / PB. Hemos visto a partir de la narrativa de la profesora que la elección de la docencia está ligada a las propias condiciones sociales y económicas de la ciudad donde reside, la influencia del modelo de profesora que tuvo cuando era niño y la relevancia de trabajar en la Educación Infantil considerando los diferentes aprendizajes de los alumnos en su contexto específico. Finalmente, esta actividad nos posibilitó pensar la elección de la docencia a partir de una mirada más cuidadosa acerca de la formación y de los principales aspectos que la influencian.

PALABRAS CLAVE: Formación Docente; Educación Infantil; Elección de la profesión.

\section{INTRODUÇÃO}

Este artigo faz parte de uma atividade avaliativa da disciplina de Fundamentos e Metodologia da Educação Infantil II, no Curso de Pedagogia/UAE/CFP/UFCG ${ }^{2}$, com uma carga horária de $90 \mathrm{~h} / \mathrm{a}$ e temos como objetivos discutir as principais influências para a escolha da profissão docente, levando em consideração a contribuição das experiências

${ }^{2}$ UAE/Unidade Acadêmica de Educação, CFP/Centro de Formação de Professores, UFCG/Universidade Federal de Campina Grande, campus Cajazeiras/PB. 
vividas e as limitações no que diz respeito às oportunidades de emprego/trabalho na cidade onde residimos, bem como reconhecer a importância dos vínculos estabelecidos entre professores e alunos para o processo de ensino-aprendizagem e identificar os principais aspectos vividos nas experiências escolares que contribuíram de forma agradável e/ou desagradável refletidas na prática docente.

Realizamos uma entrevista semiestruturada com uma professora que trabalha na Educação Infantil na cidade de Carrapateira/PB - a professora Madalena, nome fictício desenvolve suas atividades docentes em uma Escola pública municipal de Ensino Infantil e Fundamental.

O que nos levou a selecionar a professora foi o diferencial no desenvolvimento de uma prática pedagógica de excelência, com muitos anos de experiência na Educação Infantil e é reconhecida como uma das melhores na cidade, por pais, alunos, colegas de trabalho, e pela comunidade em geral. Madalena é conhecida pela forma de desenvolver o seu trabalho incentivando a autonomia das crianças, através das atividades lúdicas e dinâmicas, tornando a sala de aula um ambiente significativo e propiciador de novos conhecimentos.

Outro fato que nos chamou a atenção foi à forma como a professora trata os seus alunos, a partir da importância do afeto, do tratar bem, do acolhimento e do respeito às diferenças, pois sabemos que a Educação Infantil é uma etapa fundamental para o desenvolvimento da criança.

Percebemos que apesar de muitos anos como professora da Educação Infantil ela não se conforma com o cotidiano repetitivo, nem com o modelo de ensino tradicional que é caracterizado pela transmissão de conteúdos, em que o professor é o ponto central, aquele que possui o saber, e o aluno é aquele que não sabe e deve apenas escutar, e aprender a reproduzir, mas pelo contrário busca ser mediadora do aprendizado, defende que o professor deve estar aberto a respeitar e valorizar os saberes dos educandos, não só para repassar o que sabe, mas por meio de uma troca de conhecimento entre docente e discentes possam construir a prática educativa e busca trazer o novo para a sala de aula, tornando a sua prática cada vez mais atrativa e dinâmica.

A professora Madalena é graduada em Pedagogia pela Universidade Federal de Campina Grande, especialista em Psicopedagogia pela Faculdade São Francisco na Paraíba e participa de formação continuada na cidade onde reside. Com isso, vimos que sua formação 
está de acordo com a Lei de Diretrizes e Bases da Educação Nacional (LDB, 9.394/96) quando diz que a "[...] formação de docentes para atuar na educação básica far-se-á em nível superior, em curso de licenciatura, de graduação plena, em universidades e institutos superiores de educação [...]" (Art. 62).

Esta Lei é um grande avanço na educação brasileira, pois quando olhamos para a história da formação de professores para a Educação Infantil no Brasil, vimos que ela é quase inexistente, porque esta etapa da educação traz consigo desde o início um caráter assistencialista, em que as creches e pré-escolas funcionavam como um depósito onde os pais deixavam seus filhos enquanto trabalhavam. Desta forma, as pessoas que trabalhavam com crianças visavam somente à questão do cuidar, considerando a higiene pessoal, alimentação e sono, porém, a LDB 9.394/96 em seu Art. 29 afirma que a

[...] educação infantil, primeira etapa da educação básica, tem como finalidade o desenvolvimento integral da criança de até 5 (cinco) anos, em seus aspectos físico, psicológico, intelectual e social, complementando a ação da família e da comunidade (BRASIL, 1996).

Dessa forma, esta modalidade da educação e a formação de seus professores ganham um novo rumo, em que se faz necessário um profissional capacitado, que estude sobre o desenvolvimento das crianças; que conheça a importância da indissociabilidade do cuidar e do educar. Podemos acrescentar a esta discussão, ainda, a importância do brincar que favoreça uma prática educativa que incentive a criatividade, a curiosidade, o respeito à diversidade, levando em consideração a forma como as crianças aprendem, e as suas características culturais, sociais, étnicas e de gênero, para tanto é preciso uma prática que possa contemplar o seu desenvolvimento integral, minimizando a visão tradicional de ensino.

\section{FORMAÇÃO DE PROFESSORES PARA A EDUCAÇÃO INFANTIL: UM PANORAMA HISTÓRICO.}

Apresentaremos, neste artigo, os principais aspectos históricos da formação de professores, de forma, ainda, incipiente, apresentando as políticas públicas e seus avanços, 
para que possamos refletir a formação de professores nos dias atuais e as principais influências históricas que, ainda, estão presentes em nossa educação.

A formação de professores para a Educação Infantil vem sendo alvo de debates no meio educacional, principalmente após o surgimento de políticas públicas que trazem avanços significativos para a concepção de criança, infância, e Educação Infantil, como a Constituição Federal de 1988, o Estatuto da Criança e do Adolescente de 1990 e a Lei de Diretrizes e Bases da Educação Nacional de 9.394/96, das quais trataremos mais a frente.

Sabendo da importância de ver a trajetória histórica da Educação Infantil, iniciaremos tratando do surgimento das primeiras creches no Brasil, pois segundo Alves (2011, p. 2)

No final do século XIX, foram criados os primeiros "asilos", as primeiras creches para os filhos das classes menos favorecidas, que funcionavam como "depósitos" de crianças para que as mães pudessem trabalhar. [...] sendo o trabalho ali realizado voltado para questões de higiene, alimentação e cuidados físicos, sem investimentos nos aspectos pedagógicos.

Dessa forma, a primeira proposta de uma Educação Infantil no Brasil, não tinha a preocupação com questões educacionais e muito menos com a formação específica de pessoas para trabalhar nesse espaço, pelo contrário, bastava apenas gostar de crianças e 'ter jeito' na forma de tratá-las, logo isso fez com que não houvesse uma formação específica para os professores para esta modalidade de ensino, tornando-a desnecessária. Esta realidade infelizmente está presente, ainda hoje, em muitas creches, pois muitos, ainda, a veem como um local destinado ao cuidado em que qualquer um pode trabalhar, e não como um ambiente educativo, como nos é assegurado pela LDB 9.394/96.

A pré-escola, por sua vez, atendia as crianças de 4 a 6 anos de idade, e como afirma Alves (2011, p. 4, apud LOBO, 2011, p. 142)

O enfoque do atendimento nesse período era assistencial e compensatório, caracterizado pelo 'esquecimento' dos recursos humanos e pela ausência de projetos e propostas do governo e de criação de cursos de formação para o profissional.

Portanto, a pré-escola não se diferenciava do atendimento das creches, servia mais como uma preparação para o ensino escolar, deixando de lado a questão educacional e a preparação de professores para atuarem nessa fase. 
Por outro lado, no que diz respeito às políticas públicas, a década de 80 trouxe avanços para a educação, pois com a Constituição Federal de 1988, considerada a constituição cidadã, a educação começa a ser dever do Estado, conforme assegura o seu Art. 205 quando afirma que

A educação, direito de todos e dever do Estado e da família, será promovida e incentivada com a colaboração da sociedade, visando ao pleno desenvolvimento da pessoa, seu preparo para o exercício da cidadania e sua qualificação para o trabalho. (BRASIL, 1988).

Além de garantir em seu Art. 206, inciso I a “[...] igualdade de condições para o acesso e a permanência na escola" e a "liberdade de aprender, ensinar, pesquisar e divulgar o pensamento, a arte e o saber" no inciso II (BRASIL, 1988).

Sem dúvida esta Lei traz consigo avanços significativos para a educação brasileira, que ganha um novo foco, pois passa a visar o desenvolvimento pleno do individuo, além de que quando trata da igualdade de condições não só para o acesso, mas também para a permanência, reconhece que vivemos em uma sociedade desigual, em que somente a igualdade de direitos não basta, mas que é preciso dar condições para que as pessoas possam usufruir desse direito, proporcionando mais direitos e recursos a quem tem menos, para que dessa forma todos possam ter as mesmas oportunidades.

Dois anos depois, em 1990, temos a criação do Estatuto da Criança e do Adolescente (ECA), que assegura todos os direitos das crianças e adolescentes, trazendo conquistas importantes para a Educação Infantil. Destacaremos a seguir, alguns dos pontos do ECA que consideramos importantes, focando, principalmente, a educação. Em seu Art. 4 o ECA assegura que

É dever da família, da comunidade, da sociedade em geral e do poder público assegurar, com absoluta prioridade, a efetivação dos direitos referentes à vida, à saúde, à alimentação, à educação, ao esporte, ao lazer, à profissionalização, à cultura, à dignidade, ao respeito, à liberdade e à convivência familiar e comunitária (BRASIL, 1990).

Um primeiro ponto que refletiremos é o fato das crianças passarem a ser consideradas sujeitos de direitos, já que historicamente não eram reconhecidas dessa forma, e durante muito tempo não se tinha nenhuma Lei que garantisse os direitos assegurados acima. Outro 
fato importante é que o cumprimento destes não é dever somente de um ou outro órgão público, mas de toda a sociedade, além de que estes direitos são garantidos a todas as crianças, independente de raça, gênero ou classe social.

No que se refere à educação, assim como na Constituição Federal de 1988, o ECA assegura em seu Art. 53 que "[...] a criança e o adolescente têm direito à educação, visando ao pleno desenvolvimento de sua pessoa, preparo para o exercício da cidadania e qualificação para o trabalho" (BRASIL, 1990). Ainda no parágrafo único deste artigo, vimos que “[...] é direito dos pais ou responsáveis ter ciência do processo pedagógico, bem como participar da definição das propostas educacionais" (BRASIL, 1990).

Com relação à cultura, podemos destacar que no Artigo 58 do Estatuto da Criança e do Adolescente dispõe que "[...] no processo educacional respeitar-se-ão os valores culturais, artísticos e históricos próprios do contexto social da criança e do adolescente, garantindo-se a estes a liberdade da criação e o acesso às fontes de cultura.” (BRASIL, 1990).

Com isso, são visíveis os avanços que o ECA trouxe para o meio educacional, pois garante o respeito às crianças, a sua identidade, além de que amplia a participação da família na definição dos processos educacionais, e busca dar ênfase a cultura dos alunos e a sua história. Vale ressaltar que este documento não trata diretamente da formação de professores para atuar na Educação Infantil, porém, essas novas concepções de criança, de infância e de educação, que surgiram a partir da Constituição Federal de 1988 e do ECA de 1990, contribuíram de forma positiva para a reformulação da Lei de Diretrizes e Bases da Educação Nacional em 1996, a qual trataremos a seguir.

A Lei de Diretrizes e Bases da Educação Nacional (LDB/1996) passou por muitas reformulações desde o seu surgimento, sendo sempre adaptada de acordo com o tempo histórico vivido. A LDB 9.394/96 é reconhecida como a legislação mais completa da educação brasileira, e sem dúvidas ocasionou mudanças relevantes na formação de profissionais para a Educação Infantil, trazendo especificidades. Em seu Art. 29 temos na LDB que a

[...] educação infantil, primeira etapa da educação básica, tem como finalidade o desenvolvimento integral da criança de até 5 (cinco) anos, em seus aspectos físico, psicológico, intelectual e social, complementando a ação da família e da comunidade (BRASIL, 1996). 
Dessa forma, o reconhecimento da Educação Infantil como parte da educação básica, traz consigo a necessidade de formação específica para esta etapa, diferente da formação voltada para o modelo tradicional de ensino, em que um bom professor é aquele que controla a sua turma, mantém os alunos calados e transferem os conhecimentos dos livros didáticos. A formação de professores ganha um novo caminho, nesse se faz necessário conhecer cada etapa do desenvolvimento infantil, para que possamos de fato promover uma educação que leve o desenvolvimento do indivíduo de forma integral e que principalmente reconheça a indissociabilidade entre o cuidar e o educar, logo, essa percepção leva um novo desafio para as instituições de ensino superior, pois precisam contemplar a especificidade da Educação Infantil, e assim formarem profissionais capacitados a contribuir com a finalidade da Educação Infantil determinada pela LDB 9.394/96.

O Plano Municipal de Educação (PME) da cidade de Carrapateira-PB, local onde realizamos a entrevista, no que se refere à formação de professores para a educação básica, almeja "[...] que todos os professores e as professoras da educação básica possuam formação específica de nível superior, obtida em curso de licenciatura na área de conhecimento em que atuam (PME CARRAPATEIRA/PB, 2015, p. 94).

Ainda afirmam que buscarão garantir aos “[...] profissionais da educação básica formação continuada em sua área de atuação, considerando as necessidades, demandas e contextualizações dos sistemas de ensino" (PME CARRAPATEIRA/PB, 2015, p. 95).

Contudo, para refletir sobre a formação e a prática docente dos profissionais da Educação Infantil nos dias atuais, se faz necessário, em primeiro lugar, pensar sobre a formação que os cursos de licenciatura em Pedagogia estão proporcionando. Segundo Amorim (2016) a partir da aprovação da resolução CNE/CP nº 1/2006 os cursos de Pedagogia passaram a formar professores para a Educação Infantil, mas ainda afirma que "[...] poucos cursos propõem disciplinas que permitam algum aprofundamento em relação à educação infantil" (AMORIM, 2016, p.163, apud GATTI, 2010, p. 18). Com isso, vemos que um dos desafios na atualidade é levar a especificidade da Educação Infantil para os cursos de formação de professores para esta etapa.

Um ponto a ser pensado que contribuirá para a melhoria da prática docente na Educação Infantil, é a formação continuada, que deve possibilitar ao docente o aprofundamento na especificidade desta etapa da educação básica. 
Podemos pensar que para que os professores da Educação Infantil desempenhem uma boa prática docente, é necessário que os cursos de licenciatura em Pedagogia proporcionem aos futuros professores uma formação de qualidade, em que contemple a Educação Infantil, e suas especificidades, dando ênfase às fases de desenvolvimento das crianças, e quebrando com a visão assistencialista que essa fase historicamente carrega consigo, e que as Secretarias Municipais de Educação possam proporcionar formações continuadas aos professores, para que possamos de fato entender que "[...] na Educação Infantil é preciso sim ter professor e de que este precisa ter uma formação sólida, de boa qualidade e específica para a compreensão da especificidade dessa etapa" (AMORIM, 2006, p.164).

\section{AFETIVIDADE NA PRÁTICA DOCENTE: RELATOS DE UMA PROFESSORA DA EDUCAÇÃO INFANTIL.}

Analisaremos a seguir uma entrevista semiestruturada voltadas para a formação do professor da Educação Infantil, buscando refletir os principais aspectos que influenciaram a construção da identidade docente da professora Madalena, que possui graduação em Pedagogia e Especialização em Psicopedagogia e há 20 anos exerce à docência na Educação Infantil na cidade de Carrapateira/PB. Iniciamos a entrevista perguntando como foi sua infância e a professora nos relatou:

Eu vivi o período da minha infância no sítio [...], juntamente com os meus familiares, pais, avós, tios, tias, primos e primas. E lá foi onde eu comecei a construir a minha história de vida, os laços afetivos entre os meus familiares e amigos [...] (PROFESSORA MADALENA).

Levando em consideração que a discussão da afetividade não se limita somente ao contexto escolar, a partir da fala da professora podemos compreender a importância da afetividade presente nas relações vividas com os seus familiares para a construção de sua identidade, já que “[...] os fenômenos afetivos representam a maneira como os acontecimentos repercutem na natureza sensível do ser humano, produzindo nele um elenco de reações matizadas que definem seu modo de ser-no-mundo." (TASSONI, 2006, p. 47, apud, PINO, p.130-131).

Em seguida, indagamos sobre como era a sua relação com a escola, ela então nos disse 
[...] minha relação com a escola era de fundamental importância, pois na escola eu me sentia feliz e tinha o desejo de estar lá todos os dias convivendo com os meus colegas e a professora. Sentia-me realizada através das atividades e brincadeiras vivenciadas no dia-a-dia. A escola era pra mim um lazer, minha segunda casa. A minha relação com os meus professores era ótima, porque eu sempre fui uma aluna que gostava de estudar, e respeitava os meus professores igualmente como os meus pais. Recordo-me de todos os momentos alegres e tristes, mas muito marcantes na minha vida (PROFESSORA MADALENA).

Com isso, é notável que a sua relação com a escola era algo estimulante, isso é importante, pois é dever da escola proporcionar este ambiente acolhedor, em que as crianças se sintam bem, pois isto influencia de forma positiva no aprender, já que o aluno "[...] só aprende quando quer aprender e só quer aprender quando vê na aprendizagem algum sentido" (GADOTTI, 2003, p. 07). Só aprendemos quando nos sentimos bem acolhidos e vemos sentido no que está sendo estudado, principalmente quando há respeito na relação professor e alunos.

Outro fator relatado pela professora, que nos chamou à atenção, foi a sua relação com os seus professores que era baseada no respeito e não no autoritarismo, isso sem dúvidas influencia a aprendizagem, pois de acordo com Freire (1996) é importante o querer bem aos alunos, o carinho e a dedicação, pois são aspectos fundamentais para o processo de ensinoaprendizagem.

No momento em que questionamos se havia algum professor que marcou sua vida, ela mencionou que:

Sim. A professora que marcou a minha trajetória estudantil chamava-se Rosa, ela contribuiu muito para o meu aprendizado e para a vida. Através da simplicidade e do jeito que ela tratava meus colegas e eu, com muita atenção e carinho fez com que todos nós sentíssemos capazes de realizar as atividades, despertando em nós o desejo de fazer e aprender. Rosa se expressava muito bem, gostava de brincar, cantava muito, ela sempre nos acolhia com um "boa tarde", lembro-me que sempre que a gente chegava lá na parte da tarde a porta estava fechada, mas quando ela nos via na janela parava o que estava fazendo, corria, vinha abrir a porta e tinha a maior satisfação de receber a gente, a acolhida dela era muito boa. Nunca esqueci o seu jeito, tão paciente e manso. Hoje em sala de aula, Rosa é uma influência pra mim na questão de como tratar e também na forma de receber as crianças (PROFESSORA MADALENA). 
Suas palavras nos fez perceber o quanto ela gostava da professora Rosa, pela influência que teve em sua aprendizagem e para sua prática como professora da Educação Infantil. Dessa forma, não poderíamos deixar de destacar a discussão sobre afetividade na relação professor-aluno que vem ganhando cada vez mais ênfase no ambiente educacional, através dos estudos teóricos e pesquisas em diferentes âmbitos.

Tendo em vista que as relações afetivas interferem diretamente o comportamento, e que estão presentes nas relações sociais, se faz necessário que a escola e os professores, façam com que a afetividade se manifeste de forma positiva em suas relações com os alunos, para isso é importante que o professor entenda que a afetividade está ligada a capacidade de afetar, ou seja, pode se manifestar de forma positiva ou negativa, e dessa forma não confunda afetividade com práticas como: beijar e abraçar os alunos frequentemente, mas que possa entender que a afetividade se manifesta de diversas formas, principalmente através da atenção, incentivo, e da maneira como o professores e alunos se expressam, seja verbalmente ou não, enfim é preciso compreender que "[...] não podemos pensar uma sala de aula isenta de sentimentos e emoções" (TASSONI, 2006, p. 69).

Quando a docente Madalena afirma que a professora Rosa fez com que todos se sentissem capazes de realizar as atividades, despertava o desejo de fazer e aprender e que ela se expressava muito bem, ela ressalta justamente uma boa relação estabelecida entre ela e seus colegas, através da atenção, do incentivo, acolhimento e de sua forma de tratá-los tão marcante que ainda hoje, Rosa é lembrada e é uma grande influência em sua prática docente.

Em outro momento perguntamos o que a levou a escolher a profissão docente e obtivemos o seguinte relato:

Era meu sonho desde criança, nas brincadeiras, eu sempre imitava o professor. Outro aspecto que influenciou foi que o nosso lugar toda vida foi carente e o único emprego que tinha era de professor. Aos dezessete anos, quando cursava a $8^{\text {a }}$ série, recebi a proposta de ser professora da Educação Infantil e aceitei o desafio, fui trabalhando e gostando. Entrei na universidade em 2006, pelo PEC, um programa do governo que dava acesso à universidade a quem já era professor e não tinha formação [...] (PROFESSORA MADALENA). 
Estes relatos nos remetem a discussões que consideramos importantes, pois aqui trataremos das às principais influências tanto para escolha da profissão, quanto para a construção da identidade docente.

Uma das questões que nos deixou pensativas foi justamente a forma que ela fala sobre a escolha da profissão, que neste caso, trata-se de uma escolha acompanhada pela falta de opção do lugar onde reside, Madalena retrata a realidade de muitas cidades pequenas, e de muitos professores, que além de não terem opções, assumiram um emprego como professores de Educação Infantil sem nenhuma formação em nível superior.

Por outro lado, quando Madalena afirma que "foi trabalhando e gostando", nos remete à construção da identidade docente, que deve ser entendida como um processo contínuo e inacabado, tendo em vista que ela "[...] vai se forjando em diferentes tempos/espaços e não tem como único lócus o curso de Formação de Professores" (JESUS, 2000, p. 28), ou seja, o ser professor vai muito além da conclusão de um curso de licenciatura, pois estamos a todo o momento nos construindo professores, através da teoria, da prática e de diferentes reflexões.

Finalizamos a entrevista questionando sobre como ela se percebe professora da Educação Infantil, e ela nos respondeu afirmando:

Hoje me considero uma excelente professora da Educação Infantil, porque construí o meu caminho docente através dos meus exprofessores da formação superior, e de outras formações continuada, das experiências adquiridas ao longo da minha história como educadora e da prática continuada em sala de aula. [...] Porém, percebo que necessito crescer na profissão [...], pois ensinar nos dias de hoje não é tarefa fácil, exige que o professor esteja preparado, atualizado para enfrentar os desafios impostos pela sociedade (PROFESSORA MADALENA).

Madalena reconhece que as experiências vividas tanto na sua graduação, quanto nas formações continuadas e na sua prática diária, contribuíram para definir como ela se sente em sua profissão hoje. Outro fator que vale ressaltar é que ela tem consciência do inacabamento quando afirma que necessita crescer e que o professor deve estar sempre se atualizando, isso é essencial, pois como afirma Freire (1996, p. 14) "Não há ensino sem pesquisa e pesquisa sem ensino. Esses que-fazeres se encontram um no corpo do outro". 
No que se diz respeito à prática educativa, Madalena busca sempre promover um ambiente em que os alunos possam exercer sua autonomia e afirma que sempre dá a “oportunidade de se expressarem” (PROFESSORA MADALENA). Por fim, Madalena acrescenta: "Creio também na questão da troca de conhecimento, pois a criança vem recheada de conhecimento de mundo, cabe à escola, ao professor, resgatar e explorar".

Com essas palavras ela traz uma questão que para muitos professores é um grande desafio, acreditar que "Quem ensina aprende ao ensinar e quem aprende ensina ao aprender" (FREIRE, 1996, p. 12), já que muitos docentes, ainda, promovem sua prática educativa baseada no autoritarismo, em que se vê como o único que possui o saber e que este precisa ser transmitido. Essa concepção tem sido perpassada ao longo das gerações e precisa ser repensada para obtermos outro olhar acerca da docência e o papel do professor.

Notamos que a professora busca construir laços afetivos com os seus alunos em sua prática, quando ressalta: “[...] acredito na importância do afeto, do tratar bem, e do respeito às diferenças" (PROFESSORA MADALENA). Contudo, acreditamos que como afirma Freire (1996, p. 53) "A prática educativa é tudo isso: afetividade, alegria, capacidade científica, domínio técnico a serviço da mudança ou, lamentavelmente, da permanência do hoje”.

\section{CONSIDERAÇÕES FINAIS}

Até aqui tivemos o propósito de desenvolver um breve apanhado histórico sobre a formação de professores para a Educação Infantil, para que, a partir dessa reflexão, pudéssemos compreender que muitos dos desafios presentes hoje nesta modalidade da educação básica, são frutos das concepções que permearam, historicamente a formação docente e vimos a necessidade de superar alguns entendimentos que, ao nosso ver, comprometem a qualidade do ensino de crianças em suas mais diferentes faixas etárias.

O curso de Pedagogia é sem dúvida um dos meios para ultrapassarmos o entendimento da visão assistencialista e tradicional que a Educação Infantil carrega desde o seu surgimento até os dias atuais. Para tanto é preciso buscarmos "[...] uma concepção que entende os alunos como aprendizes ativos, tendo o professor o papel de criar condições favoráveis para a ampliação de seus conhecimentos [...]" (CAMPOS, 1999, p. 137). 
Dessa forma, podemos destacar que uma das principais reflexões que a análise da entrevista nos proporcionou foi que os cursos de formação para professores precisam contemplar também o estudo da afetividade, já que para as crianças da Educação Infantil esta “[...] é a fase na qual a tarefa central é a formação da personalidade. É pelas relações com as pessoas que a criança vai construindo a consciência de si mesma" (TASSONI, 2006, p. 58). Logo, as relações entre professores e alunos são importantes e decisivas para o desenvolvimento da criança.

Outro fator que a entrevista nos proporcionou foi o entendimento de uma boa reflexão foi sobre como a construção da identidade docente e a escolha desta profissão são complexas, pois como já mencionado anteriormente, no caso da professora Madalena a escolha da profissão docente, não partiu somente dela, ou seja, de ser professora por que de fato queria exercer essa profissão, ou até mesmo por influência dos pais como ocorre em alguns casos, mas principalmente pelo contexto em que vivia na época, em que antes mesmo de concluir a $8^{\mathrm{a}}$ série começou a sua prática, até porque como vimos há alguns anos era comum as pessoas que moravam em cidades pequenas se tornarem professores sem ter uma formação específica.

Então, para Madalena não bastou, apenas, brincar de ser professora para que se tornasse, nem muito menos estudar com bons professores para que ela desejasse essa profissão, mas o que condicionou foi todo um processo social e econômico que fez com que ela escolhesse essa profissão. Portanto, não podemos desconsiderar a influência de sua professora para sua prática docente, pois como ela mesma nos relatou, carrega consigo os seus ensinamentos na forma de tratar seus alunos.

Por fim, a realização deste trabalho nos proporcionou uma experiência única para pensarmos a formação da professora da Educação Infantil para além do que vemos ou ouvimos na sociedade, que, de certa foram, desmerece e desrespeita essa profissão.

\section{REFERÊNCIAS BIBLIOGRÁFICAS}

AMORIM. Ana Luisa Nogueira. Formação de professores de educação infantil no alto sertão paraibano. In: LOPES, Wiama de Jesus Freitas. SANTIAGO, Stela Márcia de Morais (orgs.). Formação de professores e identidades docentes em questão: o que nos ensina os 35 anos de pedagogia no alto sertão paraibano. Fortaleza: Imprece, 2016. p. 159-177.

ALVES. Bruna Molisani Ferreira. Infâncias e educação infantil: aspectos históricos, legais e pedagógicos. Revista Aleph Infâncias. ISSN 1807-6211. Ano V, n. 16, nov/2011. Disponível em: <http://www.uff.br/revistaleph/pdf/art8.pdf>. Acesso em: 24 mar. 2017. 
BRASIL. Lei de Diretrizes e Bases da Educação Nacional. Lei no 9.394, de 20 de dezembro de 1996. Disponível em: <http://www.planalto.gov.br/ccivil_03/leis/L9394.htm>. Acesso em: 14 mar. 2017.

BRASIL. Constituição (1988). Constituição da República Federativa do Brasil. de 05 de outubro de 1988.10 Disponível em: <http://www.planalto.gov.br/ccivil_03/constituicao/constituicaocompilado.htm> . Acesso em: 17 mar. 2017.

BRASIL. Estatuto da criança e do adolescente: Lei federal no 8069, de 13 de julho de 1990. Disponível em: <http://www.planalto.gov.br/ccivil_03/leis/L8069.htm>. Acesso em: 21 mar. 2017.

CAMPOS. Maria Malta. A formação de professores para crianças de $\mathbf{0}$ a 10 anos: modelos em debate. Educ. Soc. [online]. 1999, vol.20, n.68, p.126-142. Disponível em: 〈http://www.scielo.br/pdf/es/v20n68/a07v2068.pdf〉. Acesso em: 05 abr. 2017.

CARRAPATEIRA. Plano Municipal de Educação - PME/Secretaria Municipal de Educação. Maio, 2015.

FREIRE, Paulo. Pedagogia da Autonomia - Saberes Necessários à Prática Educativa. 25 . ed. São Paulo: Paz e terra, 1996.

GADOTTI, Moacir. Boniteza de um sonho: ensinar-e-aprender com sentido. São Paulo: GRUBHAS. 2003.

JESUS. Regina Fátima. Sobre alguns caminhos trilhados... ou mares navegados... Hoje, sou professora. In: VASCONCELOS. Geni Amélia Nader (org.). Como me fiz professora. Rio de Janeiro: DP\&A, 2000. p. 21-41.

TASSONI. Elvira Cristina Martins. Dimensões afetivas na relação professor-aluno. In: LEITE, Sérgio Antônio da Silva (org.). Afetividade e práticas pedagógicas. $1^{\mathrm{a}}$ ed. São Paulo: Casa do Psicólogo, 2006. p. 47-74. 